\title{
The effect of various canal contents on the accuracy of two electronic apex locators in detecting different size of root perforations
}

\author{
Tulin Dogan Cankaya ${ }^{1}{ }^{\mathbb{D}}$, Zeliha Ugur Aydin² ${ }^{\mathbb{D}}$, Demet Altunbas ${ }^{3}$ \\ ${ }^{1}$ Alanya Alaaddin Keykubat University, Faculty of Dentistry, Department of Endodontics, Antalya, Turkey. \\ ${ }^{2}$ Bolu Abant Izzet Baysal University, Faculty of Dentistry, Department of Endodontics, Bolu, Turkey. \\ ${ }^{3}$ Sivas Cumhuriyet University, Faculty of Dentistry, Department of Endodontics, Sivas, Turkey.
}

Correspondence Author: Zeliha Ugur Aydin

E-mail: zlhugur@gmail.com

Received: $19.05 .2020 \quad$ Accepted: 30.05 .2021

\begin{abstract}
Objective: This study was to investigate the effect of different canal contents on the accuracy of Gold Reciproc Motor (GRM; VDW, Munich, Germany) and DentaPort ZX (Morita Co, Kyoto, Japan) in the determination of artificial root perforations.

Methods: Forty mandibular premolar teeth were included in this study. The crowns of the teeth were removed and the root lengths were standardized to be $14 \pm 1 \mathrm{~mm}$. Roots were divided into 2 groups $(n=20)$. Artificial root perforations were created $0.5 \pm 0.1 \mathrm{~mm}$ and $1 \pm 0.1 \mathrm{~mm}$ in size respectively. The actual lengths (AL) up to the perforation areas were measured under the stereomicroscope. Electronic measurements (EL) were obtained by GRM and DentaPort ZX in dry conditions and the presence of $\mathrm{NaOCl}(5.25 \%)$, EDTA (17\%) and blood. The difference was calculated by subtracting the ALs from the ELs. This difference was positive when the measurement was longer than the AL and negative when the measurement was shorter. The Friedman and Wilcoxon signed-rank tests were used to analyze the data $(p<0.05)$.

Results: There were no significant differences amongst the different intracanal conditions for both apex locators in teeth with perforation of 1 $\mathrm{mm}$. In the teeth with a perforation of $0.5 \mathrm{~mm}$ DentaPort ZX measurements were not affected by intracanal conditions and the most accurate measurement was obtained when the canal was dry with GRM.

Conclusion: Within the limitation of this study, intracanal conditions did not affect the measurements of DentaPort ZX in both perforation sizes, whereas in $0.5 \mathrm{~mm}$ perforation size, GRM measurements were affected by intracanal conditions. .
\end{abstract}

Keywords: Blood, DentaPort ZX, Gold Reciproc motor, irrigation solutions, root perforation.

\section{INTRODUCTION}

Apical root perforation is defined as an artificial opening that constitutes a nonanatomical pathway between the root canal system and periodontal tissues. Root perforation may occur due to excessive use of a rigid file having cut tip, over the instrumentation of a curved root canal, inappropriate preparation of the post cavity and pathological conditions such as external or internal root resorption $(1,2)$. It has been reported that apical root perforation is an important complication occurring in the root canal treatment with a frequency of $3-10 \%$ (3). After perforation, the bacterial infection that spreads from the root canal to the periodontal tissues, from the periodontal tissues to the root canal or from both, affects the healing by causing pain, swelling, suppuration and resorption of the bone. In addition, a rapid periodontal loss may occur with the expansion of the gingival epithelium into the perforation zone (4). But early diagnosis and treatment can improve prognosis $(5,6)$.
It is important to know the localization of the perforation so that the root canal preparation, intracanal medicament application and repair of the perforation area can be made appropriately. Localization of the perforation can be determined by the use of paper points for indirect detection of the bleeding point, direct observation of bleeding and the use of devices such as conventional periapical radiography, cone beam computed tomography (CBCT) and electronic apex locator $(E A L)(1,7)$. Small-sized perforations on the buccal or lingual surface of the tooth may not be detected in traditional radiographs because it displays anatomical structures in only two dimensions. (5). EALs are frequently preferred by dentists because of the advantages such as greatly reducing the number of radiography taken and increasing patient comfort (8). EALs can identify cases where there is a connection between the root canal and the periodontium, such as root fractures, cracks and internal or external resorption (1). 
The use of these devices to determine the working length was first proposed by Custer and the electrical resistance characteristics of the oral tissues were improved after examination by Suzuki $(9,10)$. DentaPort ZX (Morita Co, Kyoto, Japan) a third-generation EAL, calculates and reports the ratio of two different frequencies simultaneously (11). Also, it was reported that the accuracy of measurement by DentaPort ZX was not affected by vital pulp tissue and exudate $(12,13)$. The Gold Reciproc Motor (GRM) (VDW $\mathrm{GmbH}$, Munich, Germany) is an endodontic engine with an integrated electronic apex locator. The integrated EAL can be used both during preparation and separately (14). This study aimed to evaluate the reproducibility and accuracy of two EALs in the presence of various canal contents ( $\mathrm{NaOCl}$, EDTA, saline and human blood) and simulated two different size root perforations. The null hypothesis of the study; in the case of root perforations of two different sizes, one with a diameter of $0.5 \mathrm{~mm}$ and one $1 \mathrm{~mm}$, there is no difference between the accuracy of the two EALs in the presence of different irrigations in the root canal.

\section{METHODS}

The study design was approved by Abant Izzet Baysal University Clinical Researches Ethics Committee (2019/207). After power calculation based on a similar methodological study, 20 mandibular premolar teeth were included for each perforation size in this study. The same samples were used for each irrigation solution and each EAL in both groups in order to ensure standardization in applications (1).

Forty mandibular premolar teeth with a single root and single canal extracted for orthodontic and periodontal reasons were included in the study. Periapical radiographs were taken for buccolingual and mesiodistal directions for each tooth, and it was confirmed that the root canal development of the teeth was complete, there was no calcification, fracture and no root canal treatment. The calculus on the tooth surfaces was cleaned with a periodontal curette. Following sample selection, the teeth were disinfected for 48 hours at $4{ }^{\circ} \mathrm{C}$ in solution of $2.5 \% \mathrm{NaOCl}$ (Endosolv $\mathrm{Hp}$; Imıcryl, Konya, Turkey). Teeth were stored in $0.1 \% \mathrm{NaOCl}$ until used in the study.

The endodontic access cavity was prepared and then the apical patency was checked using the \# $10 \mathrm{~K}$ type file (Dentsply Maillefer, OK, USA). To obtain a fixed reference point and standardization during the measurements, the crowns of the teeth were removed by the diamond drill (Diatech, Charleston, USA) under water cooling. The roots were standardized to $14 \pm 0.1 \mathrm{~mm}$. The working length was determined to be $1 \mathrm{~mm}$ shorter than the apical foramen using the \# $10 \mathrm{~K}$ type file. Canals were prepared up to the 25 size using $\mathrm{K}$ type file. After preparation, the canals were irrigated with $2 \mathrm{ml}$ of $5.25 \% \mathrm{NaOCl}$ followed by $2 \mathrm{ml}$ of distilled water and dried with paper points (DiaDent Group, Chongju, Korea). 40 teeth were randomly numbered and divided into two groups, each consisting of 20 teeth;
Group 1: Drill was placed at the proximal surface of the roots at a distance of $4 \pm 0.1 \mathrm{~mm}$ from the apical and at a 90-degree angle and artificial perforation areas were created with a diameter $0.5 \pm 0.1 \mathrm{~mm}$.

Group 2: Drill was placed at the proximal surface of the roots at a distance of $4 \pm 0.1 \mathrm{~mm}$ from the apical and at a 90-degree angle and artificial perforation areas were created with a diameter $1 \pm 0.1 \mathrm{~mm}$. The diameter of the perforation areas was verified by electronic caliper (Mitutoya, Kawasaki, Japan).

Before the electronic measurement (EL) stage, the actual lengths $(A L)$ of the canals up to the perforation area were measured by using the \# $25 \mathrm{~K}$ type file at $20 \mathrm{X}$ magnification under the stereomicroscope (Stemi DV4; Carl Zeiss, Gottingen, Germany). To mimic the periodontal ligament during EL, the teeth were embedded in alginate (Blueprint, Dentsply, England) and the lip clip was contacted with alginate during measurement. When canals were dry and the presence of the NaOCl, EDTA (IMICRYL, Konya, Turkey) and human blood in canals, EL measurements were made using DentaPort ZX and GRM.

For the EL, the \# $25 \mathrm{~K}$ type file was placed inside the canal and when the last green line signal was seen in both EALs, the stopper of the file was brought to the reference point and this length measurement using endodontic ruler (MiniEndo-Bloc; Dentsply Maillefer) and recorded as EL. All measurements for solutions were made after irrigating the canals with $2.5 \mathrm{ml}$ of fresh solution. Canals were irrigated with $5 \mathrm{ml}$ of distilled water and dried with paper points to completely remove the previous remaining solution between the different solution groups. All irrigation procedures were performed with a lateral perforated needle (31 gauge NaviTip Sideport; Ultradent Products Inc., South Jordan, UT, USA). Finally, measurements were made in the presence of human blood (within 4 hours) in the canal. Blood was drawn from the healthy volunteer $(20 \mathrm{ml})$ and was stored in EDTA anticoagulant-containing tubes (K2EDTA blood tube, BD Vacutainer ${ }^{\circledR}$, Plymouth, UK), preventing coagulation, both before and during the procedure. Each measurement was repeated 3 times and the mean of these 3 values were determined as EL. All measurements were made by the same operator experienced in the use of EAL.

\section{Statistical Analysis}

All statistical analyses were performed using SPSS for Windows (ver. 16.0, SPSS Inc., Chicago, IL, USA). The Friedman and Wilcoxon signed-rank tests were used to analyze the data. The significance was determined at $p<0.05$.

\section{RESULTS}

There were no significant differences among the different intracanal conditions for both apex locators in teeth with perforation of $1 \mathrm{~mm}$ (for GRM group: $\mathrm{p}=0.49$; for DentaPort ZX group: $p=0.65$ ) (Table 1 ). In the teeth with a perforation 
of $0.5 \mathrm{~mm}$ DentaPort ZX measurements were not affected by intracanal conditions $(p=0.07)$ and the most accurate measurement was obtained when the canal was dry with GRM $(p<0.001)$ (Table 2). Also, there was no significant difference between the two apex locators in the presence of all intracanal irrigants in teeth with perforation of $1 \mathrm{~mm}$ and $0.5 \mathrm{~mm}$ ( $p>0.05)$.

Table 1. Mean values of the difference between the electronic lengths and the actual lengths of the group with $1 \mathrm{~mm}$ perforation

\begin{tabular}{|l|c|c|c|c|} 
& $\begin{array}{c}\mathrm{NaOCl} \\
\text { Mean } \pm \text { SD }\end{array}$ & $\begin{array}{c}\text { EDTA } \\
\text { Mean } \pm \text { SD }\end{array}$ & $\begin{array}{c}\text { Blood } \\
\text { Mean } \pm \text { SD }\end{array}$ & $\begin{array}{c}\text { Dry } \\
\text { Mean } \pm S D\end{array}$ \\
\hline Dentaport ZX & $0.27 \pm 0.58^{\mathrm{ax}}$ & $0.35 \pm 0.52^{\mathrm{ax}}$ & $0.28 \pm 0.64^{\mathrm{ax}}$ & $0.27 \pm 0.55^{\mathrm{ax}}$ \\
\hline GRM & $0.20 \pm 0.50^{\mathrm{ax}}$ & $0.33 \pm 0.56^{\mathrm{ax}}$ & $0.49 \pm 0.82^{\mathrm{ax}}$ & $0.30 \pm 0.52^{\mathrm{ax}}$ \\
\hline
\end{tabular}

SD: standard deviation; Significant differences between columns $(a, b)$ and lines $(x, y)$ are indicated by superscripts.

Table 2. Mean values of the difference between the electronic lengths and the actual lengths of the group with $0.5 \mathrm{~mm}$ perforation

\begin{tabular}{|l|l|l|l|l|} 
& $\begin{array}{l}\text { NaOCl } \\
\text { Mean } \pm \text { SD }\end{array}$ & $\begin{array}{l}\text { EDTA } \\
\text { Mean } \pm \text { SD }\end{array}$ & $\begin{array}{l}\text { Blood } \\
\text { Mean } \pm \text { SD }\end{array}$ & $\begin{array}{l}\text { Dry } \\
\text { Mean } \pm \text { SD }\end{array}$ \\
\hline Dentaport ZX & $0.65 \pm 0.74^{\text {ax }}$ & $0.84 \pm 0.67^{\text {ax }}$ & $0.54 \pm 0.87^{\text {ax }}$ & $0.73 \pm 0.93^{\text {ax }}$ \\
\hline GRM & $1.07 \pm 2.10^{\text {ax }}$ & $0.87 \pm 1.134^{\text {ax }}$ & $1.05 \pm 1.01^{\text {bx }}$ & $0.009 \pm 0.62^{\text {by }}$ \\
\hline
\end{tabular}

SD: standard deviation; Significant differences between columns $(a, b)$ and lines $(x, y)$ are indicated by superscripts.

\section{DISCUSSION}

During the root canal treatment, root perforations may occur due to various procedures. It is important to localize root perforations for the success of endodontic treatment (15). In the detection of root perforations, radiographs are frequently used in endodontics. However, Shemesh et al. (16) demonstrated that periapical radiographs were very limited in their ability to detect root perforations and that even CBCT could not detect certain perforations. Considering this situation, the use of EALs which do not expose the patient to ionizing radiation in the detection of root perforations is advantageous. In this study, in the presence of four different canal contents, the accuracy of two different EALs was investigated in the determination of localization of artificial root perforations having two different sizes.

In vitro studies on EALs have suggested the use of different embedding environments that simulate the electrical resistance of human tissues. Therefore, it has been suggested to use $\% 2$ agars, gelatin, saline solution and alginate to mimic the clinical situation in in-vitro studies (17-22). Baldi et al. (23) reported that different dental embedding environments (alginate, gelatin, saline solution, sponge, agar) did not affect the accuracy of EAL. In contrast, Chen et al. (24) found that alginate was more successful in the accuracy of EALs than sugar-free gelatin and $9 \%$ sodium chloride. In the current study, similar to that of Altunbaş et al. $(5,11)$, Chen et al. (24) and Tinaz et al. (25), the teeth were embedded in alginate, an electroconductive material that is easy to prepare and costeffective.
There are differences in the results of studies investigating the accuracy of EAL in different canal conditions in the literature. Marigo et al. (26) reported that DentaPort ZX and Raypex 6 did highly accurate measurements without being affected by the presence or absence of $\mathrm{NaOCl}$ on human cadavers. Ebrahim et al. (27) reported that the accuracy of DentaPort ZX was not affected by the canal content in determining the working length. Similarly, Duran-Sindreu et al. (9) reported that $\mathrm{NaOCl}$ and $\mathrm{CHX}$ did not affect the accuracy of IPEX and Root ZX in determining the working length. Li et al. (28) also reported that EALs were not affected by the canal contents in the determination of the localization of the artificial perforation areas. In accordance with the results of these studies, DentaPort ZX in two perforation sizes and GRM in $1 \mathrm{~mm}$ perforation size were not affected by the presence of different canal contents. In contrast to these findings, Altunbaş et al. (5) reported that Dentaport ZX was more accurate in the presence of EDTA compared to $\mathrm{NaOCl}$ in detecting the localization of $1.5 \mathrm{~mm}$ diameter perforation. The differences between the results may be due to factors such as the diameter and location of the perforation and EAL selection. However, GRM gave the best result in dry conditions in localization of $0.5 \mathrm{~mm}$ perforation. Considering this situation, it is thought that GRM can give misleading results in the presence of irrigant or bleeding in the canals with small perforated teeth.

In the present study, there was no difference between DentaPort ZX and GRM in determining the localization of 1 $\mathrm{mm}$ perforation. However, in determining the localization of $0.5 \mathrm{~mm}$ perforation, DentaPort ZX in the presence of blood and GRM in dry conditions was more accurate. To the best of our knowledge, there is no study comparing the accuracy of DentaPort ZX and GRM in the literature. Therefore, the results of our study could not be directly compared with other studies. The reason why two devices give different results in dry conditions and the presence of blood can be explained by the different working principles of EALs. Similar to Tinaz et al. (25) and Gomes et al. (29), in this study, some standard deviation (SD) values were found to be high (in presence of $\mathrm{NaOCl}$ solution in the canal to localize the $1 \mathrm{~mm}$ perforation with GRM). This situation can be related to the claim that the accuracy of EALs mentioned earlier in the literature is affected by root canal anatomy (30). The literature reported that low SD shows the consistency of EALs. $(6,9)$ In this study, both DentaPort ZX and GRM had a lower SD in all canal conditions compared to $0.5 \mathrm{~mm}$ perforations in localization of $1 \mathrm{~mm}$ perforation. This situation showed that both EALs were more reliable in detecting $1 \mathrm{~mm}$ perforation. In some studies $(1,8)$, investigating the accuracy of EALs, $\pm 0.5 \mathrm{~mm}$ was accepted as an acceptable error range, while in some studies (31) the tolerance ranges of $\pm 1 \mathrm{~mm}$ were accepted. In this study, DentaPort ZX had an acceptable error range in all groups. In contrast, GRM had a larger SD than the error range accepted in the literature in the presence of $\mathrm{NaOCl}$, EDTA, and blood at $0.5 \mathrm{~mm}$ perforation. 


\section{CONCLUSION}

Within the limitations of this study, there was no difference between DentaPort ZX and GRM in determining the localization of $1 \mathrm{~mm}$ perforation. In the presence of $\mathrm{NaOCl}$, EDTA and blood in the canal, the DentaPort ZX showed more reliable results in determining the localization of $0.5 \mathrm{~mm}$ perforation. In light of this information, we think that the use of DentaPort ZX may give the clinician more accurate diagnosis and treatment planning in small perforated teeth. The use of GRM may be disadvantageous in cases where bleeding with perforated teeth cannot be stopped for localization of perforation.

\section{Acknowledgments}

This research was presented at the $20^{\text {th }}$ Scientific Congress of the Asian Pacific Endodontic Confederation \& the 14th International Congress of the Turkish Endodontic Society (Istanbul, Turkey / April 24-27, 2019).

\section{REFERENCES}

[1] Nazari Moghaddam K, Nazari S, Shakeri L, Honardar K, Mirmotalebi F. In vitro detection of simulated apical root perforation with two electronic apex locators. Iran Endod J 2010;5:23-26.

[2] Marroquin BB, Fernandez CC, Schmidtmann I, Willershausen B, Goldberg F. Accuracy of electronic apex locators to detect root canal perforations with inserted metallic posts: an ex vivo study. Head Face Med 2014;10:57.

[3] Kaufman AY, Fuss Z, Keila S, Waxenberg S. Reliability of different electronic apex locators to detect root perforations in vitro. Int Endod J 1997;30:403-407.

[4] Siew K, Lee AH, Cheung GS. Treatment outcome of repaired root perforation: A systematic review and meta-analysis. J Endod 2015;41:1795-804.

[5] Altunbas D, Kustarci A, Toyoglu M. The Influence of Various Irrigants on the Accuracy of 2 Electronic Apex Locators in Locating Simulated Root Perforations. J Endod 2017;43:439442.

[6] D’Assuncao FL, Sousa JC, Felinto KC, de Medeiros TC, Leite DT, de Lucena RB, de Oliveira Lima J. Accuracy and repeatability of 3 apex locators in locating root canal perforations: an ex vivo study. J Endod 2014;40:1241-1244.

[7] Ustun $Y$, Aslan T, Sekerci AE, Sagsen B. Evaluation of the Reliability of Cone-beam Computed Tomography Scanning and Electronic Apex Locator Measurements in Working Length Determination of Teeth with Large Periapical Lesions. J Endod 2016;42:1334-1337.

[8] Angwaravong O, Panitvisai P. Accuracy of an electronic apex locator in primary teeth with root resorption. Int Endod J 2009;42:115-121.

[9] Duran-Sindreu F, Gomes S, Stober E, Mercade M, Jane L, Roig M. In vivo evaluation of the iPex and Root ZX electronic apex locators using various irrigants. Int Endod J 2013;46:769-774.

[10] Duran-Sindreu F, Stöber E, Mercadé M, Vera J, Garcia M, Bueno $R$, Roig $M$. Comparison of in vivo and in vitro readings when testing the accuracy of the Root ZX apex locator. J Endod 2012;38:236-239.
[11] Altunbas D, Kustarci A, Arslan D, Er K, Kocak S. Comparison of various current electronic apex locators to determine the working length using the clearing technique. Niger J Clin Pract 2015;18:359-363.

[12] Erdemir A, Eldeniz AU, Ari H, Belli S, Esener T. The influence of irrigating solutions on the accuracy of the electronic apex locator facility in the Tri Auto ZX handpiece. Int Endod J 2007;40:391-397.

[13] Goldberg F, De Silvio AC, Manfre S, Nastri N. In vitro measurement accuracy of an electronic apex locator in teeth with simulated apical root resorption. J Endod 2002;28:461463.

[14] Wigler R, Huber R, Lin S, Kaufman AY. Accuracy and reliability of working length determination by Gold Reciproc Motor in reciprocating movement. J Endod 2014;40:694-697.

[15] Tsesis I, Rosenberg E, Faivishevsky V, Kfir A, Katz M, Rosen E. Prevalence and associated periodontal status of teeth with root perforation: a retrospective study of 2,002 patients' medical records. J Endod 2010;36:797-800.

[16] Shemesh H, Cristescu RC, Wesselink PR, Wu MK. The use of cone-beam computed tomography and digital periapical radiographs to diagnose root perforations. J Endod 2011;37:513-516.

[17] Nahmias $Y$, Aurelio JA, Gerstein H. An in vitro model for evaluation of electronic root canal length measuring devices. J Endod 1987;13:209-214.

[18] Donnelly JC. A Simplified Model to Demonstrate the Operation of Electronic Root-Canal Measuring Devices. J Endod 1993;19:579-580.

[19] Ushiyama J. New principle and method for measuring the root canal length. J Endod 1983;9:97-104.

[20] Weiger R, John C, Geigle H, Lost C. An in vitro comparison of two modern apex locators. J Endod 1999;25:765-768.

[21] Meares WA, Steiman HR. The influence of sodium hypochlorite irrigation on the accuracy of the Root ZX electronic apex locator. J Endod. 2002;28:595-598.

[22] Kaufman A, Katz A. Reliability of Root ZX apex locator texted by an in vitro model. J Endod 1993;19:201.

[23] Baldi JV, Victorino FR, Bernardes RA, de Moraes IG, Bramante $\mathrm{CM}$, Garcia RB, Bernardineli N. Influence of embedding media on the assessment of electronic apex locators. J Endod 2007;33:476-479.

[24] Chen E, Kaing S, Mohan H, Ting SY, Wu J, Parashos P. An ex vivo comparison of electronic apex locator teaching models. J Endod 2011;37:1147-1151.

[25] Tinaz AC, Alacam T, Topuz O. A simple model to demonstrate the electronic apex locator. Int Endod J 2002;35:940-945.

[26] Marigo L, Gervasi GL, Somma F, Squeo G, Castagnola R. Comparison of two electronic apex locators on human cadavers. Clin Oral Investig 2016;20:1547-1550.

[27] Ebrahim AK, Wadachi R, Suda H. An in vitro evaluation of the accuracy of Dentaport ZX apex locator in enlarged root canals. Aust Dent J 2007;52:193-197.

[28] Li YH, Zhou Z, Zheng YQ, Gan N, Tang YY, Li R, Chen J. Accuracy of three different electronic apex locators in determination of perforation with various conditions in vitro. Hua Xi Kou Qiang Yi Xue Za Zhi 2011;29:272-275.

[29] Gomes S, Oliver R, Macouzet C, Mercadé M, Roig M, DuranSindreu F. In vivo evaluation of the Raypex 5 by using different irrigants. J Endod 2012;38:1075-1077. 
[30] Ding J, Gutmann JL, Fan B, Lu Y, Chen H. Investigation of apex locators and related morphological factors. J Endod 2010;36:1399-1403.
[31] Shabahang S, Goon WW, Gluskin AH. An in vivo evaluation of Root ZX electronic apex locator. J Endod 1996;22:616-618.

How to cite this article: Dogan Cankaya T, Ugur Aydin Z, Altunbas D. The Effect of Various Canal Contents on the Accuracy of Two Electronic Apex Locators in Detecting Different Size of Root Perforations. Clin Exp Health Sci 2021; 11:258-262. DOI: 10.33808/ clinexphealthsci.739588 